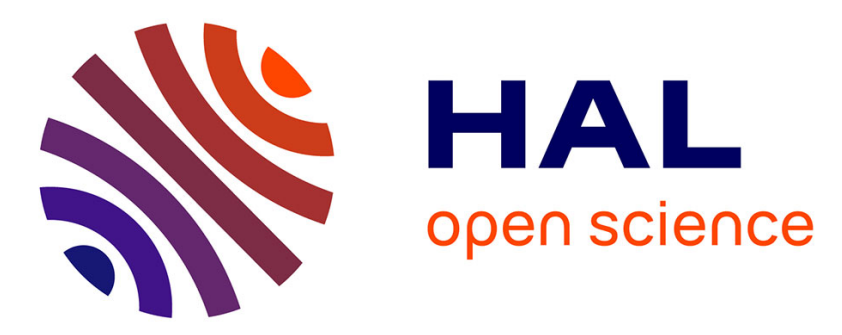

\title{
Structure of the water-splitting photocatalyst oxysulfide $\alpha$-LaOInS2 and ab initio prediction of new polymorphs
}

\author{
Houria Kabbour, Adlane Sayede, Sébastien Saitzek, Gauthier Lefevre, Laurent
}

Cario, Martine Trentesaux, Pascal Roussel

\section{- To cite this version:}

Houria Kabbour, Adlane Sayede, Sébastien Saitzek, Gauthier Lefevre, Laurent Cario, et al.. Structure of the water-splitting photocatalyst oxysulfide $\alpha$-LaOInS2 and ab initio prediction of new polymorphs. Chemical Communications, 2020, 56 (11), pp.1645-1648. 10.1039/C9CC09797J . hal-02485636

\section{HAL Id: hal-02485636 \\ https://hal.science/hal-02485636}

Submitted on 15 Dec 2020

HAL is a multi-disciplinary open access archive for the deposit and dissemination of scientific research documents, whether they are published or not. The documents may come from teaching and research institutions in France or abroad, or from public or private research centers.
L'archive ouverte pluridisciplinaire HAL, est destinée au dépôt et à la diffusion de documents scientifiques de niveau recherche, publiés ou non, émanant des établissements d'enseignement et de recherche français ou étrangers, des laboratoires publics ou privés. 


\section{Structure of the water-splitting photocatalyst oxysulfide $\alpha$ - $\mathrm{LaOlnS}_{2}$ and $a b$ initio prediction of new polymorphs}

Received 00th January 20xx, Accepted 00th January 20xx

DOI: $10.1039 / x 0 x \times 00000 x$

\author{
Houria Kabbour, ${ }^{* a}$ Adlane Sayede ${ }^{b}$, Sébastien Saitzek ${ }^{b}$, Gauthier Lefèvre ${ }^{b}$, Laurent Cario ${ }^{c}$, Martine \\ Trentesaux $x^{a}$ and Pascal Roussel ${ }^{a}$
}

\begin{abstract}
We unveil the structure and investigate the visible light watersplitting photocatalyst $\alpha$-LaOlnS 2 , the second polymorph in this composition. This remarkable oxysulfide exhibits rare mixed anion $\operatorname{InS}_{5} \mathrm{O}$ octahedra leading to both $0-2 p$ and $S-3 p$ hybridized with indium states in the vicinity of the Fermi level. $A b$ initio structure prediction shows the stability of such heteroleptic environments and points other hypothetical polymorphs.
\end{abstract}

Amidst oxychalcogenides, a large diversity of properties has been evidenced making them among the most promising candidates to design functional materials, ${ }^{1}$ including those for sustainable energy. ${ }^{2}$ However, they remain under-investigated compared with oxide solids. With their distinct anions exhibiting different radius and electronegativities, mixed anion compounds tend to offer low dimensional structures associated to anionic segregation into different layers ${ }^{3}$. As well illustrated for instance by Clarke et $\mathrm{al}^{4}{ }^{4}$ this type of $2 \mathrm{D}$-structuration can lead to original magnetic and electronic properties, for instance in the large family made of perovskite oxide blocks stacked with antifluorite type sulfide blocks. ${ }^{5}$ In addition, several wide band gap phases containing $\mathrm{Cu}$-chalcogenide-layers such as $\mathrm{Sr}_{2} \mathrm{ZnO}_{2} \mathrm{Cu}_{2} \mathrm{~S}_{2}{ }^{6}$ or $\mathrm{LaOCuS}^{7}$ may be doped to generate holes at the top of the valence band made of hybridized $\mathrm{Cu} 3 d$ and $\mathrm{S} 3 p$ states, leading to $p$-type conduction. While oxysulfides are increasingly investigated for a variety of properties (thermoelectricity ${ }^{8}$, superconductivity ${ }^{9}$, optical properties ${ }^{10}$ such as luminescence ${ }^{11} \ldots$...), they also seem promising for photocatalysis ${ }^{12-13}$. In particular, due to the different contributions to the valence band of several anions, anionic

\footnotetext{
a. Univ. Lille, CNRS, Centrale Lille, ENSCL, Univ. Artois, UMR 8181 - UCCS - Unité de Catalyse et Chimie du Solide, F-59000 Lille, France

b. Univ. Artois, CNRS, Centrale Lille, ENSCL, Univ. Lille, UMR 8181 - UCCS - Unité de Catalyse et Chimie du Solide, F-59000 Lille, France

c. Institut des Matériaux Jean Rouxel (IMN), Université de Nantes, CNRS, 2 rue de la Houssinière, 44322 Nantes Cedex 3, France

Electronic Supplementary Information (ESI) available: [Crystallographic data for $\alpha$ $\mathrm{LaOInS}_{2}$ and predicted structures, experimental and theoretical details]. See DOI: $10.1039 / x 0 \times x 00000 x$
}

band gap engineering should be possible in this way to design band gap tuned photocatalysts ${ }^{14}$.

Considering chalcogenides, they are attractive in that purpose compared to oxides as they can offer narrow band gap suitable for photocatalysis under visible-light irradiation, e.g. CulnS ${ }_{2}{ }^{15}$. However, as pointed for instance by Wang et al. ${ }^{16}$ and ref. therein with sulfides the self-oxidation of sulfur anions competes with the oxidation reaction of water to produce $\mathrm{O}_{2}$ resulting in nonstoichiometric water-splitting reactions. But this effect may be overcome with oxysulfides that are more stable. The same authors have recently shown the outstanding performances of $\mathrm{Y}_{2} \mathrm{Ti}_{2} \mathrm{O}_{5} \mathrm{~S}_{2}$ oxysulfide (bandgap of $1.9 \mathrm{eV}$ ) as photocatalyst for overall water splitting under visible light and could optimize the conditions to obtain the concomitant and stoichiometric production of hydrogen and oxygen ${ }^{16}$. Few other oxychalcogenides systems have been pointed recently, such as $\mathrm{LaOlnS}_{2}$. The first phase identified with this composition, named hereafter $\alpha$-LaOInS 2 , was reported in 2004 with the unit cell parameters $a=20.5421$ (6) $\AA, b=14.8490$ (4) $\AA$ and $c=3.9829(1)$ $\AA$ in space group Pbnm obtained from a pure powder sample for which neither direct methods nor trial and error method enabled a structure determination ${ }^{17}$. Ogisu et al. ${ }^{18}$ have evidenced the visible light driven photocatalytic activity for overall water splitting of this sample following the synthetic method reported in ref. 17 while the structure remains unknown. They have also shown an enhancement of both $\mathrm{O}_{2}$ and $\mathrm{H}_{2}$ evolution using co-catalysts, $\mathrm{IrO}_{2}$ and $\mathrm{Pt}$ respectively. More recently, another polymorph of $\mathrm{LaOInS}_{2}$ with a band gap of $2.64 \mathrm{eV}$ was reported with similar properties by Miura et al. ${ }^{19}$ on the basis of the structure initially targeted in ref. 17. Using the metathesis reaction $\mathrm{LaOCl}+\mathrm{NaInS}_{2} \rightarrow \mathrm{LaOlnS}_{2}+\mathrm{NaCl}$, they could successfully stabilize this metastable form composed by the stacking of alternating sulfide [ $\left.\mathrm{InS}_{2}\right]$ layers (rock-salt type) and oxide [LaO] layers (PbO-type). Here, we note the anionic segregation into different layers. Within the system La-O-In-S, the structure of the phases $\mathrm{La}_{5} \mathrm{In}_{3} \mathrm{~S}_{9} \mathrm{O}_{3}$ (band gap $\left.\sim 2.60 \mathrm{eV}\right)^{17}$ and $\mathrm{La}_{10} \mathrm{In}_{6} \mathrm{~S}_{17} \mathrm{O}_{6}{ }^{20}$ were also reported but were obtained in the 
form of single crystals only. In those phases and the elucidated $\mathrm{LaOInS}_{2}$, Indium is exclusively surrounded by sulfur.

In this article, we determine the structure of the unsolved polymorph $\alpha$-LaOInS 2 (with same composition but different structure) that proved visible light overall water splitting activity. The presence of a rare mixed anion environment (heteroleptic) in one Indium site $\mathrm{InS}_{5} \mathrm{O}$ is discussed in relation with the DFT computed band gap features. Finally, using an Evolutionary Algorithm (EA) based code we propose new hypothetical structural models within the $\mathrm{LaOInS}_{2}$ composition that exhibit heteroleptic environments. These results should

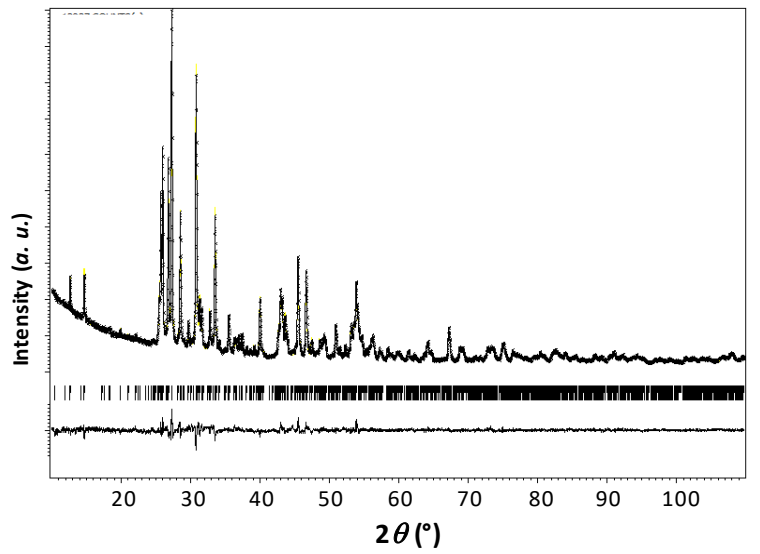

pave the way to the development of new functional candidates for visible light photocatalysis with tuned band gap.

Fig. 1 a) Powder XRD Rietveld refinement of $\alpha$-LaOInS

The powder synthesis of $\alpha$-LaOlnS 2 phase was performed following the procedure described in the reference 17 . The structure resolution was carried out from a high resolution powder XRD pattern with the refined unit cell parameters $a=$ 3.9850(2) $\AA, b=20.5460$ (13) $\AA$ and $c=14.8477(10) \AA$ and the space group $P m c n$, equivalent to the unit cell in space group Pbnm used for the profile fitting reported in 17. A structural model could be found using the charge flipping procedure of the SUPERFLIP program as implemented in the Jana2006 suite ${ }^{21}$ Then, Rietveld refinements combined with Fourier differences maps analysis were carried out to achieve a first structural model. At this stage, oxide anions were missing to reach the expected formulation $\mathrm{LaOlnS}_{2}$. Based on the knowledge of related structures in the La-O-In-S phase diagram, we placed $\mathrm{O} 3$ in the La-O sub-lattice and performed a DFT full relaxation that led to a converged model. The relaxed position was then incorporated successfully in the experimental model to achieve a high quality Rietveld refinement with the reliability factors $R_{\text {obs }}=0.0205, w R_{\text {obs }}=0.0257, R_{a l l}=0.0213, w R_{\text {all }}=0.0258$ and GOF $=1.54$, and Tables S2 and S3.

The photocatalytic activity was measured (see S1) for sake of comparison with the literature. The results (Fig. 3a) show greater detection in the presence of our catalyst and under a Xe lamp $100 \mathrm{~W}$ irradiation, which may be attributable to the $\mathrm{H}_{2}$ production. We observe a reproducible behavior with an estimate of a $\mathrm{H}_{2}$ production of $5.1 \mu \mathrm{mol} . \mathrm{h}^{-1}$. This result is fairly well correlated with the previously reported study on this phase ${ }^{18}$ and on the layered LaOInS 2 polymorph ${ }^{19}$. XPS analysis before/after the photocatalytic test proved a stable sample (see
S8). We have also estimated the band edge positions (Fig. 2a), as detailed in S7, which are encompassing the redox potentials of water as required to evolve hydrogen and oxygen. Moreover, a p-type semiconductor behavior is found from the MottSchottky (MS) plot (Fig. 2b) with a flat band potential $E_{f b}$ estimated to $1.46 \mathrm{~V}$ (vs. NHE) in good agreement with the calculated VB band edge. Details of the methodology and more

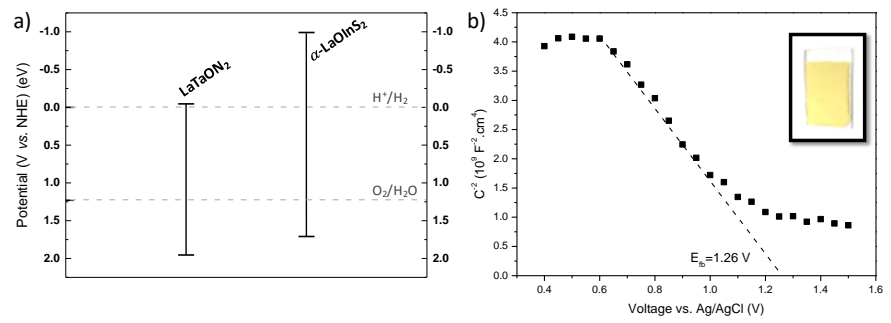

discussion are in $\mathbf{5 9 .}$

Fig. 2 a) Calculated band edges positions for the title phase $\alpha$-LaOlnS 2 and for $\mathrm{LaTaON}_{2}$ for comparison. The levels for hydrogen and oxygen evolution are indicated by dashed lines. b) Mott-Schottky plots for LaOInS 2 film deposited on ITO/Glass performed at $1 \mathrm{kHz}$.

The reported form of $\mathrm{LaOlnS}_{2}$, in contrast with the title $\alpha$ phase, exhibits a simple layered structure that can be described by $(\mathrm{LaO})$ and $\left(\mathrm{InS}_{2}\right)$ layers as mentioned in the introduction while the structures of $\mathrm{La}_{5} \mathrm{In}_{3} \mathrm{~S}_{9} \mathrm{O}_{3}$ and $\mathrm{La}_{10} \mathrm{In}_{6} \mathrm{~S}_{17} \mathrm{O}_{6}$ are more complex. They have been rationalized in reference 17 and are composed of $\mathrm{NaCl}$-type slabs and fluorite-type ribbons alternating regularly with a corrugated sulfur monoatomic layer. Slight modifications of those building blocks imbrication are at the origin of the different structures and space groups.

The title phase $\alpha$-LaOInS $S_{2}$ is unique in the La-O-In-S system as it shows a 3D structuration. It is constituted by the same basic units but differently imbricated. In particular, the fluorite type ribbons are alternating in different directions and the indiumbased polyhedral network encircles them as highlighted on figure 3. In the La sublattice, La-O distances are in the range of 2.09-2.77 ̊. For the shortest, Similar La-O distances are reported in $\mathrm{La}_{3} \mathrm{TaO}_{7}{ }^{22 a}$ (with the shortest distances of 2.094 and $2.169 \AA$ ) or $\mathrm{La}_{4} \mathrm{Ti}_{3} \mathrm{Fe}_{0.5} \mathrm{Nb}_{0.5} \mathrm{O}_{14}{ }^{22 \mathrm{~b}}$ (La-O distances starting at $2.135 \AA$ A). Then, there are three different Indium sites In1-2-3, with the environments pictured on figure $3 c$ and the distances detailed in table S4. $\ln 1 S_{4}$ tetrahedra $(T d)$ are found with In-S distances in the range $\sim 2.244$ to $2.664 \AA$. This rather distorted $\mathrm{Td}$ with $\mathrm{In}^{3+}$ slightly off-centered from one $\mathrm{S}_{3}$ face can be found in the layered $\mathrm{LaOInS}_{2}$ but also in $\mathrm{La}_{5} \mathrm{In}_{3} \mathrm{~S}_{9} \mathrm{O}_{3}$. On another hand $\ln 2 \mathrm{~S}_{6}$ octahedra are found with $\mathrm{d}_{(\mathrm{In}-\mathrm{S})} \sim 2$ 2.412-2.718 $\AA$. More interestingly, the mixed anion octahedra $\ln 3 \mathrm{~S}_{5} \mathrm{O}$ exhibits one $\mathrm{d}_{(\mathrm{In}-\mathrm{O})}=2.185 \AA$ and three $\mathrm{d}_{(\mathrm{In}-\mathrm{S})} \sim 2.392-2.689 \AA$ with another set of two longer In-S distances of 2.9015(1) Å. Considering the later heteroleptic coordination polyhedra might also be viewed as $T d+2$ rather than $O h$. This heteroleptic oxide sulfide environment around indium is uncommon, it is for instance found in the unique phase $\mathrm{Ba}_{2} \ln _{2} \mathrm{Si}_{3} \mathrm{O}_{10} \mathrm{~S} 23$ which exhibits original $\left[\ln _{2} \mathrm{O}_{7} \mathrm{~S}_{2}\right]$ dimers made of face shared $\left(\mathrm{InO}_{5} \mathrm{~S}\right)$ and $\left(\mathrm{InO}_{4} \mathrm{~S}_{2}\right)$ heteroleptic octahedra. As discussed in the later reference, oxide halide mixed environments around Indium are common contrarily to oxide sulfide environments that constitute a peculiarity. 


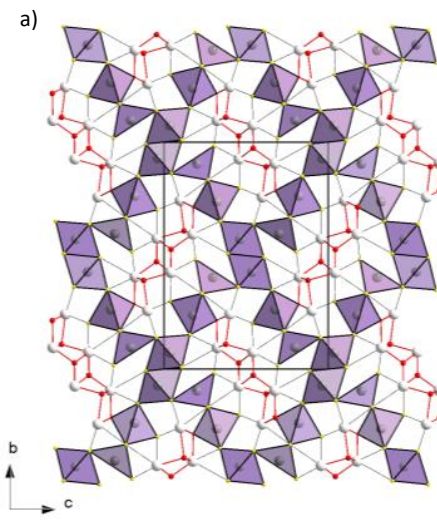

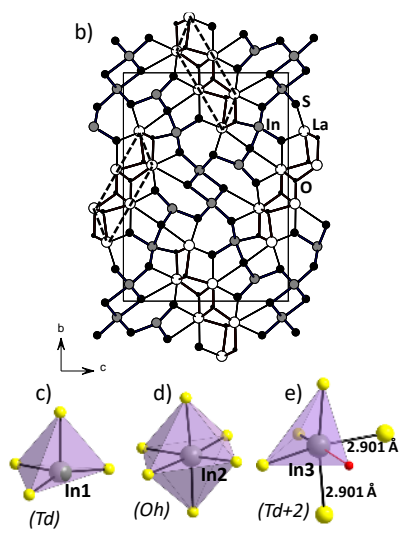

Fig. 3 Structure of $\mathrm{LaOlnS}_{2}$ a) with a polyhedral representation of the indium sub-lattice (purple) showing ( $\mathrm{PbO}$ )-type units of 3-lanthanum width (light grey spheres) in a channel-like network made of interlinked $\ln 1 \mathrm{~S}_{4}$ tetrahedron, $\ln 2 \mathrm{~S}_{6}$ and $\ln 3 \mathrm{~S}_{5} \mathrm{O}$ octahedron (sulfur in yellow and oxygen in red); b) with a similar representation than found in ref. 17 and c-d-e) detailed environments around the different indium cations sites In1-2-3

The phonons calculations based on this structure are represented on Fig. $4 \mathrm{~b}$ and clearly assess the stability of $\alpha$ $\mathrm{LaOInS}_{2}$ by the absence of negative frequencies. The density of states (DOS) are also reported in Fig. 4c. The observed band gap is underestimated compared to experience, but this is expected when using the widespread GGA-PBE functional. Here, we focus on a qualitative analysis of the valence band (VB) and of the conduction band (CB). The La $5 p, 5 d$ and $4 f$ states are found with a large contribution of the empty $4 f$ states around $4 \mathrm{eV}$ in the $\mathrm{CB}$. All these states are contributing at the top of the VB below $-1 \mathrm{eV}$ where they are hybridized with $\mathrm{O} 2 p$ states (see 01 ). A very weak contribution of the La $6 s$ states is observed. For Indium cations, In1-2-3 show similar topologies of their PDOS (see Fig. 4c and S15 with also the total DOS), with small differences such as for $\ln 3$ that exhibits a higher contribution around $-3 \mathrm{eV}$ where it hybridizes with $\mathrm{O} 2$ states not found for the other Indium cations that are exclusively surrounded by sulfur anions. More into details of $\ln 3$, the states $5 \mathrm{~s}$ are found at the bottom of the $\mathrm{CB}$ (together with the $5 p$ states) and mainly between $-5.6 \mathrm{eV}$ and $-4 \mathrm{eV}$ in the $\mathrm{VB}$. We note also a smaller contribution of the $4 d$ states. The contribution of different anions surrounding the mixed anion $\ln 3 \mathrm{~S}_{5} \mathrm{O}$ octahedron, in particular 02 , S6 (corner linking $\ln 3$ and $\ln 1$ ) and S5 pointing toward the lanthanum sub-lattice, is also highlighted on Fig. 4c. All contribute at the top of the valence band (VB) in the range of $-5.6 \mathrm{eV}$ to the Fermi level and to a lower extent at the bottom of the conduction band ( $\mathrm{CB}$ ). The maximum of the $p$ states contributions is found with respect to the Fermi level as follow $\mathrm{S} 5 \rightarrow \mathrm{S} 6 \rightarrow \mathrm{O} 2, \mathrm{O} 2(2 p)$ states lying deeper in the VB as expected from the electronegativities $\left(\chi_{0}=3.44\right.$ and $\left.\chi_{S}=2.58\right)$ and the subsequent bonding character. A push down effect of oxygen compared to a sulfide In-S matrix may occur, leading to a slightly increased band gap considering sulfur based indium polyhedrons found in related phases, i.e. the layered $\mathrm{LaOInS}_{2}$ Here, we can highlight the band gap engineering potential of varying Indium environments in those systems.

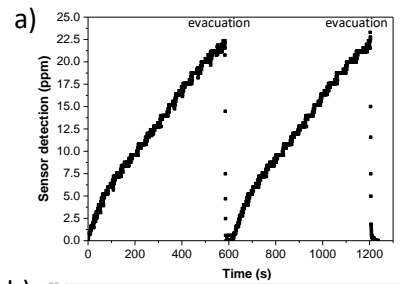

b)

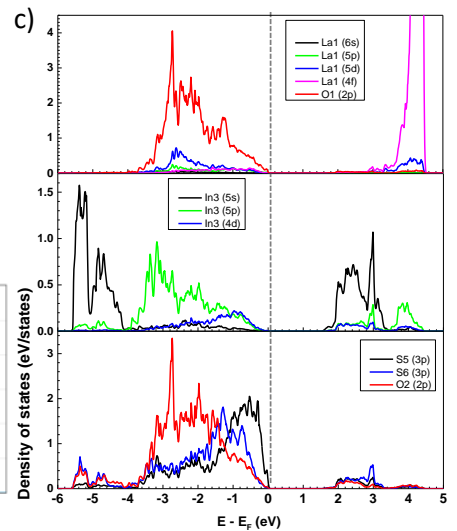

Fig. 4 a) Photocatalytic measurement of $\mathrm{H}_{2}$ evolution, b) Phonons density of states and c) Projected Density of States (PDOS) for a selection of sites in $\alpha$-LaOInS 2 with (from top to bottom) La1 states superposed with $\mathrm{O} 12 p$ states found in its environment, the heteroleptic In3 (from $\ln \mathrm{S}_{5} \mathrm{O}$ ) and below, anions involved in the later, i.e. S5, S6 and $\mathrm{O} 2 p$ states. The Fermi level is set to $0 \mathrm{eV}$ (dashed line).

Stable structures in the $\mathrm{LaOlnS}_{2}$ composition were searched by using a first-principle EA implemented in the USPEX (Universal Structure Predictor: Evolutionary Xtallography) code ${ }^{24}$. The structure prediction was carried out using the fixed composition $\mathrm{LaOInS}_{2}$ and without restriction on the unit cell. The title phase has a large unit cell ( $\sim 3$ times larger than the volume of the EA phases calculated here) which is very difficult to investigate due to computational resources limitations. Therefore the experimental structure could not be found and the prediction led to alternative structures with much smaller volumes.

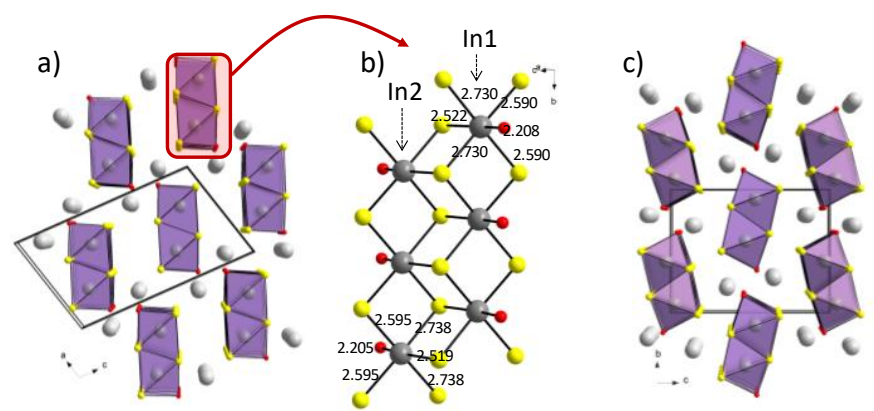

Fig. 5 Selection of structures predicted using the EA code a) the most stable one in $P 2_{1} / \mathrm{m}$. In b) details of the chain is shown (distances in $\AA$ ) around the two Indium positions. c) The NCS structure in $P 212_{1} 2_{1}$.

Here, the most stable structures reached in this way have very similar structures and differ from details of their symmetries. From the most energetically favorable to the least we have the symmetries $P 2_{1} / m(-29.961 \mathrm{eV} / \mathrm{FU})>\mathrm{P} 2_{1} / \mathrm{c}(-29.945 \mathrm{eV} / \mathrm{FU})>$ $P 2{ }_{1} 2_{1} 2_{1}(-29.845 \mathrm{eV} / \mathrm{FU}>$ Pnma (-29.824 eV/FU). Then, we will go into more details of the most stable structure and the noncentrosymmetric one $\left(P 2_{1} 2_{1} 2_{1}\right)$ while crystallographic data for all the hypothetical structures are given in the SI. As shown on figure 5, they exhibit a 1D structuration with double-chains that are arranged in a parallel manner in the most stable phase and that are slightly tilted in the non-centrosymmetric phase. As highlighted in Fig. 5b, the most prominent feature of these chains is clearly that they are made of heteroleptic (exclusively) 
$\mathrm{InS}_{5} \mathrm{O}$ octahedra sharing edges which make them of great interest to pursue. This is clearly showing the strong stability of the mixed anion environment around Indium as discovered in the title phase $\alpha$-LaOInS 2 . With volumes per formula unit smaller than the title phase (comparing DFT relaxed data), they may be stabilize trough alternative synthetic methods such as high pressure.

In this paper, we unveil the structure and investigate the oxysulfide $\alpha$-LaOInS 2 within the remarkable La-O-In-S phase diagram. Although this system has been identified with an overall water splitting photocatalytic activity, the crucial structure investigation at the basis of the properties comprehension is achieved here. In particular, we observe the rare mixed anion $\operatorname{In} \mathrm{S}_{5} \mathrm{O}$ polyhedron. It leads to the contribution of both $\mathrm{O} 2 \mathrm{p}$ and $\mathrm{S} 3 \mathrm{p}$ hybridized with indium states below the Fermi level. As the photocatalytic activity relies on the states around the band gap, it should impact the activity compared to the reported cases where indium is in a mono-anionic environment such as in the layered $\mathrm{LaOlnS}_{2}{ }^{19}$ or $\mathrm{CuInS}_{2}{ }^{15}$ for instance. In particular, it is proposed that oxysulfides should be more stable against sulfur self-oxidation during the $\mathrm{O}_{2}$ evolution reaction; here sulfur and oxygen are mixed around the strategic cation. This point deserves further investigation to relate it to the properties and the stability for the design and elaboration strategies of new candidates. Finally, EA based structure prediction leads to exclusively mixed anion environments for Indium in smaller unit cells which suggests further promising systems to investigate experimentally.

\section{Conflicts of interest}

There are no conflicts to declare.

\section{Acknowledgments}

X-Rays Diffractometers are funded by Région NPDC, FEDER, CNRS and MESR. The regional computational cluster supported by Lille University, CPER Nord-Pas-de-Calais/CRDER, France Grille CNRS and FEDER is thanked for providing computational resources.

\section{Notes and references}

1 a) J.K. Harada, N. Charles, K.R. Poeppelmeier, b, J.M. Rondinelli, Advanced Materials, 2019, 31, Article number 1805295. b) Y. Matsumoto, T. Yamamoto, K. Nakano, H. Takatsu, T. Murakami, K. Hongo, R. Maezono, H. Ogino, D. Song, C. M. Brown, C. Tassel, H. Kageyama, Angew.Chem.Int.Ed. 2019, 58, 756 -759. c) N. Zhang, J. Sun, and H. Gong, Coatings 2019, 9, 137. d) M. Wu and X. C. Zeng, NanoLett., 2017, 17, 6309-6314

2 a) S. Muhammady, Y Kurniawan, S. Ishiwata, A. Rousuli, T. Nagasaki, S. Nakamura, H. Sato, A. Higashiya, A. Yamasaki, Y. Hara, A. Rusydi, K. Takase, and Y. Darma, Inorg. Chem., 2018, 57, 10214-10223. b) S. D.N. Luu, P. Vaqueiro, Journal of Materiomics, 2016, 2, 131-140. c) Y.-Y. Li, W.-J. Wang, H.
Wang, H. Lin and L.-M. Wu, Cryst. Growth Des., 2019, 19, 4172-4192.

3 L. Cario, H. Kabbour, A. Meerschaut, Chem. Mater. 2005, 17, 234-236. H. Kabbour, E. Janod, B. Corraze, B. M. Danot, C. Lee, M.-H. Whangbo, L. Cario, J. Am. Chem. Soc. 2008, 130, 82618270

4 S. J. Clarke, P. Adamson, S. J. C. Herkelrath, O. J. Rutt, D. R. Parker, M. J. Pitcher and C. F. Smura. Inorg. Chem. 2008, 47 8473-8486.

5 C. F. Smura, D. R. Parker, M. Zbiri, M. R. Johnson, Z. A. Gal and S. J. Clarke. J. Am. Chem. Soc. 2011, 133, 2691-2705

6 H. Hirose, K. Ueda, H. Kawazoe, H. Hosono, Chemistry of Materials 2002, 14, 1037-1041

7 H. Hiramatsu, H. Kamioka, K. Ueda, H. Ohta, T. Kamiya, M. Hirano, H. Hosono. Physica Status Solidi A, 2006, 203, 28002811

8 J.-B. Labégorre, R. Al Rahal Al Orabi, A. Virfeu, J. Gamon, P. Barboux, L. Pautrot-d'Alençon, T. Le Mercier, D. Berthebaud, A. Maignan and E. Guilmeau, Chem. Mater. 2018, 30, 1085-1094

9 S.K. Singh, A. Kumar, B. Gahtori, Shruti, G. Sharma, S. Patnaik, V.P. Awana. J. Am. Chem. Soc. 2012, 134, 16504-7

10 Q. Pan, D. Yang, S. Kang, J. Qiu, G. Dong, Scientific Reports 2016, 6, Article number: 37141

11 G. Jiang, X. Wei, Y. Chen, C. Duan, M. Yin, B. Yang, W. Cao, Materials Letters, 2015, 143, 98-100.

12 a) T. Suzuki, T. Hisatomi, K. Teramura, Y. Shimodaira, H. Kobayashi and K. Domen, Phys. Chem. Chem. Phys., 2012, 14, 15475-15481. b) A. Ishikawa, T. Takata, J. N. Kondo, M. Hara, H. Kobayashi, and K. Domen, J. Am. Chem. Soc. 2002, 124, 13547-13553

13 X.-D. Tang, H.-Q. Ye, H.-X. Hu, Transactions of Nonferrous Metals Society of China (English Edition) 2013, 23 (9), 26442649

14 R. Kuriki, T. Ichibha, K. Hongo, D. Lu, R. Maezono, H. Kageyama, O. Ishitani, K. Oka, and K. Maeda, J. Am. Chem. Soc., 2018, 140, 6648-6655

15 AZ. Liu, X. Lu and D. Chen, ACS Sustainable Chem. Eng. 2018, 6, 10289-10294

16 Q. Wang, M. Nakabayashi, T. Hisatomi, S. Sun, S. Akiyama, Z. Wang, Z. Pan, X. Xiao, T. Watanabe, T. Yamada, N. Shibata, T. Takata and K. Domen. Nature Materials 2019, 18, 827-832

17 H. Kabbour, L. Cario, Y. Moëlo, and A. Meerschaut. Journal of Solid State Chemistry 2004, 177, 1053-1059

18 K. Ogisu, A. Ishikawa, K. Teramura, K. Toda, M. Hara, and K. Domen. Chemistry Letters 2007, 36, 854-855

19 A. Miura, T. Oshima, K. Maeda, Y. Mizuguchi, C. Moriyoshi, Y. Kuroiwa, Y. Meng, X.-D. Wen, M. Nagao, M. Higuchia and K. Tadanaga. J. Mater. Chem A. 2017, 5, 14270

20 L. Gastaldi, D. Carre, M.P. Pardo, Acta Crystallographica, Section B: Structural Crystallography and Crystal Chemistry 1982, 38, 2365-2367

21 Petříček, V.; Dušek, M.; Palatinus, L. Crystallographic Computing System JANA2006: General Features. Zeitschrift für Krist. - Cryst. Mater. 2014, 229, 345-352.

22 a) M. Wakeshima, H. Nishimine and Yukio Hinatsu, J. Phys.: Condens. Matter. 2004, 16, 4103. b) Yu.O. Titov, A.M. Sych, V.Ya. Markiv, N.M. Belyavina and A.O. Kapshuk. Dopov. Nats. Akad. Nauk. Ukr. (2002) 2002, 162-166

23 W.-H. Guo, X.-M Jiang, B.-W Liu, J.-W. Wu, S.-F. Li, H.-Y. Zeng, G.-C. Guo and J.-S. Huang, European Journal of Inorganic Chemistry 2016, 2016, 1846-1850

24 A. R. Oganov and C. W. Glass, J. Chem. Phys. 2006, 124, 244704. A. O. Lyakhov, A. R. Oganov, H. T. Stokes, and Q. Zhu, Comput. Phys. Commun. 2013, 184, 1172. A. R. Oganov, A. O. Lyakhov, and M. Valle, Acc. Chem. Res. 2011, 44, 227. A. Togo, F. Oba, and I. Tanaka, Phys. Rev. B 2008, 78, 134106 